Instructions for authors, subscriptions and further details:

http://rasp.hipatiapress.com

\title{
Arte y Sostenibilidad. Respuestas Artísticas ante el Colapso
}

Paula Bruna Pérez, Àngels Viladomiu Canela ${ }^{1}$

1) Facultad de Bellas Artes. Universidad de Barcelona.

Date of publication: June $3^{\text {rd }}, 2018$

Edition period: February 2018-June 2018

To cite this article: Bruna Pérez, P. \& Viladomiu Canela, A. (2018). Arte y Sostenibilidad. Respuestas Artísticas ante el Colapso. Barcelona, Research, Art, Creation, 6(2), 174-211. doi: 10.17583/brac.2018.3166

To link this article: http://dx.doi.org/10.17583/brac.2018.3166

\section{PLEASE SCROLL DOWN FOR ARTICLE}

The terms and conditions of use are related to the Open Journal System and to Creative Commons Attribution License (CC-BY). 


\title{
Art and Sustainability. Artistic Responses to the Collapse
}

Paula Bruna Pérez, Àngels Viladomiu Canela.

Faculty of Fine Arts, University of Barcelona. España

(Received: 27 December 2017; Accepted: 26 March 2018; Published: 3 June 2018)

\begin{abstract}
Theories about the collapse of contemporary societies have aroused increasing interest in recent years. Similarly, the environmental discourse has entered strongly into contemporary art, not from the naturalist or ecological approach of aforetime, but from the political ecology. Art, like other areas of knowledge, questions possible alternatives to collapse in terms of sustainability. However, given that there are two interpretations of the term sustainability, a weak one (the institutional one) and a strong one (the one defended by political ecology), it is relevant to clarify the implication of artistic projects in this sense. In the first part of this article, the scenario of the collapse of contemporary western society is presented and a parallelism with geological instability processes is established, in the context of an artistic research. Next, the types of responses to collapse are analyzed, based on ecological economy and political ecology concepts, and examples of artistic proposals are presented for each type of response. This analysis concludes on the role of contemporary art in the transition towards a sustainable society, as well as the convenience and urgency to promote artistic proposals that are framed in the concepts of strong sustainability.
\end{abstract}

Keywords: collapse, contemporary art, ecology, sustainability

2018 Hipatia Press

ISSN: 2014-8992

DOI: $10.4471 /$ brac. 2018.3166

Hipatia Press

www.hipatiapress.com

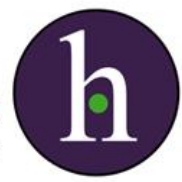




\section{Arte y Sostenibilidad. Respuestas Artísticas ante el Colapso}

Paula Bruna Pérez, Àngels Viladomiu Canela.

Facultad de Bellas Artes. Universidad de Barcelona. España

(Recibido: 27 diciembre 2017; Aceptado: 26 marzo 2018; Publicado: 3 junio 2018)

\section{Resumen}

Las teorías sobre el colapso de las sociedades contemporáneas han suscitado en los últimos años un creciente interés. Igualmente, el discurso ambiental ha entrado con fuerza en el arte contemporáneo, no ya desde el enfoque naturalista o ecologista de antaño, sino desde la ecología política. El arte, como otras áreas del conocimiento, se cuestiona posibles alternativas al colapso en términos de sostenibilidad. Sin embargo, dado que existen dos interpretaciones del término sostenibilidad, una débil (la institucional) y otra fuerte (la defendida por la ecología política), resulta relevante aclarar la implicación de los proyectos artísticos en este sentido. En la primera parte de este artículo se presenta el escenario de colapso de la sociedad occidental contemporánea y se establece un paralelismo con los procesos de inestabilidad geológica, en un contexto de investigación artística. Seguidamente, se analizan los tipos de respuestas ante el colapso, basados en los conceptos de economía ecológica y ecología política, y se exponen ejemplos de propuestas artísticas para cada tipo de respuesta. Este análisis concluye sobre el papel del arte contemporáneo en el tránsito hacia una sociedad sostenible, así como la conveniencia y la urgencia por impulsar propuestas artísticas que se enmarquen en los conceptos de sostenibilidad fuerte.

Palabras clave: colapso, arte contemporáneo, ecología, sostenibilidad.

2018 Hipatia Press

ISSN: 2014-8992

DOI: $10.4471 /$ brac. 2018.3166
Hipatia Press www.hipatiapress.com

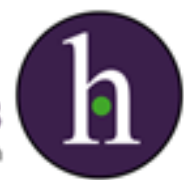




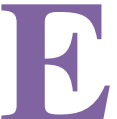

n la quinta edición de la Bienal de arte contemporáneo de Tesalónica (2015), Marina Gioti presentó As to Posterity-(2014) (vésae Imagen 1) un vídeo donde se mostraban imágenes post-apocalípticas de Grecia, y sin embargo reales. Signos del colapso contemporáneo que parece ya estar sucediendo. Como en el vídeo de Gioti, todo parece indicar que vivimos un momento de caídas y derrumbes, de fallos en el sistema, de equilibrios inestables, de señales de un colapso inminente (Diamond, 2006, p. 14).

\section{El Colapso de la Sociedad Occidental Contemporánea}

La crisis económica del 2007 (que, aunque empezó en EE.UU., con la globalización se volvió mundial) aún se arrastra. Las propuestas para solucionarla (por ejemplo, en España el "Plan E", o el rescate de los bancos), lejos de cumplir su promesa de devolvernos a la "boyante" economía de antaño, parecen insistir en las mismas causas que llevaron al problema. El consecuente aumento del desempleo (en España y Grecia el paro superó el 20\%, y el 50\% entre los jóvenes) (Dotras, 2015), junto con la subida de los impuestos, los recortes sociales y demás medidas de austeridad, han contribuido a que la crisis se trasladara al ámbito de lo social. Consecuencias: pobreza, desahucios, suicidios... Las desigualdades entre ricos y pobres están en el máximo nivel de los últimos 30 años (OECD, 2015). Por si esto fuera poco, la crisis migratoria ha alcanzado niveles sin precedentes (el año pasado hubo 65,3 millones de personas desplazadas forzosamente en todo el mundo, la mayor cifra desde la Segunda Guerra Mundial (ACNUR, 2016). Ante la incapacidad para afrontar tales problemas, las instituciones se tambalean, azotadas además por los casos de corrupción y los abusos de poder. Europa se fragmenta. Las últimas elecciones de EE.UU. han puesto en duda el tradicional sistema democrático.

A todo esto, se le suma una crisis que se ha agravado exponencialmente en las dos últimas décadas: la crisis ecológica (Taibo, 2016, p. 57). El cambio climático, la concentración de productos químicos tóxicos en el medio ambiente, la escasez de fuentes de energía, la sobreexplotación de los 
recursos naturales, la destrucción de los ecosistemas, la pérdida de biodiversidad, los problemas del suelo (erosión, salinización, y pérdida de 1 a fertilidad del suelo), los problemas de gestión del agua, y el agotamiento de la capacidad fotosintética de la tierra por parte del ser humano, podrían configurar la lista de los principales problemas ambientales a los que nos enfrentamos actualmente (Diamond 2006, pp. 395-401).

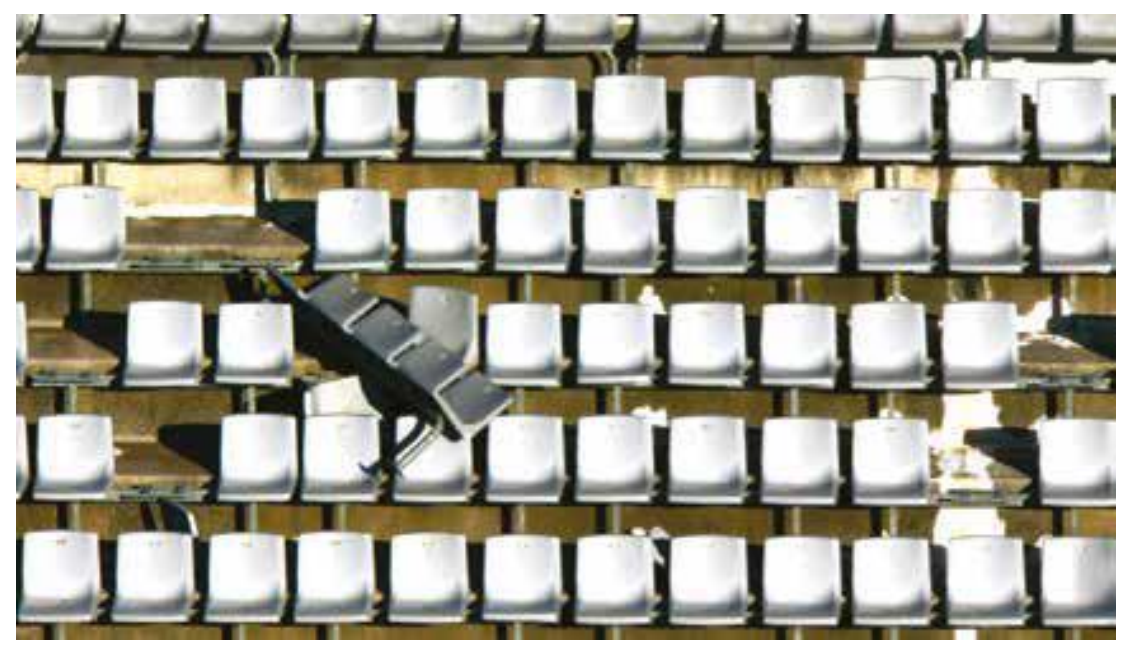

Imagen 1. Marina Gioti. As to Posterity (2014). Video monocanal, color, sonido, 12'. Fotograma recuperado de https://vimeo.com/149750589 
En resumen, citando a Servigne y Stevens, "el cambio climático se acelera, la biodiversidad se desmorona, la contaminación se extiende por todas partes, la economía corre el riesgo de padecer en cualquier momento un ataque cardíaco y las tensiones sociales y geopolíticas se multiplican" (Taibo, 2016, p. 54). ¿Estamos ante un colapso general del sistema? Es difícil afirmarlo, pero lo cierto es que, ante tales señales, cada vez son más los que alertan de que el hundimiento es probable (Taibo, 2016, p. 12). En una comparación apocalíptica, podemos llegar a simpatizar con Claire, la protagonista de la película Melancholia. (2011) (véase Imagen 2) de Lars Von Trier cuando observa, temerosa, el acercamiento de este planeta hacia la Tierra.

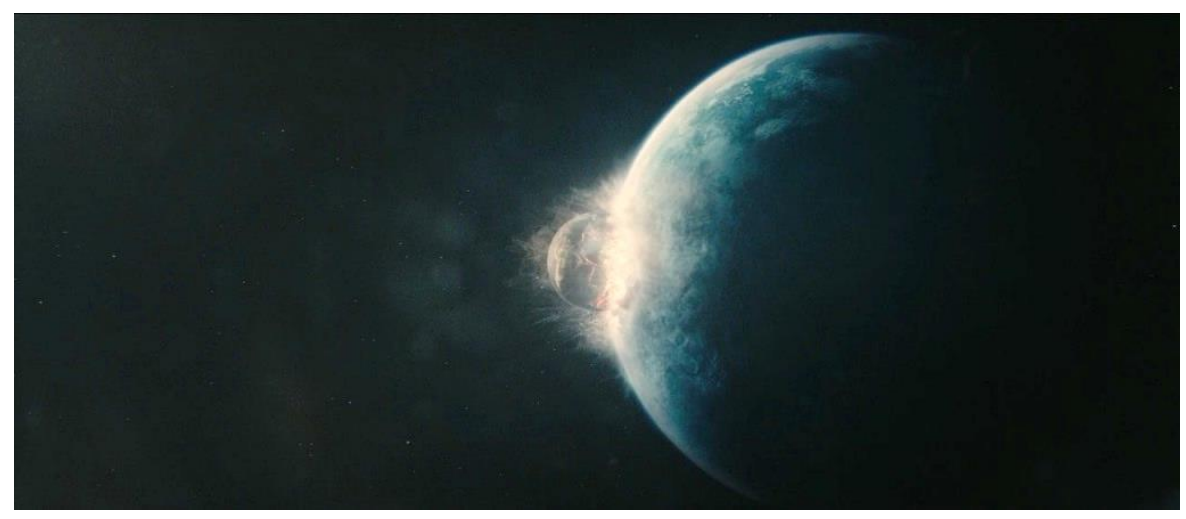

Imagen 2. Lars Von Trier. Melancholia (2011). Película, 136'. Fotograma recuperado de https://danielaugustoblog.com/2012/09/15/melancolia-e-arte/ 


\section{La Paradoja del Crecimiento Ilimitado}

El escenario de multicrisis (económica, social, institucional, política, ambiental...) pone en evidencia los fallos de un sistema gobernado por un modelo económico cuyos pilares son el crecimiento sostenido y el consumismo voraz que lo posibilita. El sistema actúa como si el crecimiento, y por ende el consumo, pudieran ser ilimitados. Pero de no ser así, rebasados los límites de estos dos pilares, el sistema colapsará.

El sueño del crecimiento infinito surge en Europa hacia 1750 con el nacimiento del capitalismo y de la economía política, y hacia 1950, con la invención del marketing y el consiguiente nacimiento de la sociedad de consumo, la utopía llegó a su plenitud (Latouche \& Harpagès, 2011, p. 13). El declive del comunismo y la globalización propiciaron la expansión y consolidación del crecimiento como objetivo indiscutible de la economía.

Consecuentemente, en todo el mundo el producto interior bruto (PIB) es el indicador por excelencia de la salud de un país, y la finalidad es su crecimiento constante. Pero, como ya advirtió en 1972 el informe Los límites del crecimiento: informe al Club de Roma sobre el predicamento de la humanidad, el crecimiento ilimitado en un mundo finito es, por definición, insostenible y destructor (Meadows, 1972). De continuar con el modelo de crecimiento, añade el informe, se podría llegar al colapso ambiental y económico en un siglo. 45 años después, el informe sigue vigente, y sus predicciones han sido apoyadas por los patrones de crecimiento, el estado del medio ambiente y el uso de recursos.

De manera premonitoria, Georges Méliès ofrece una gran metáfora visual de la imposibilidad del crecimiento ilimitado en su película L'homme à la tête en caoutchouc (1901) (véase Imagen 3), donde un joven científico avaricioso hace crecer más y más la cabeza inflable del propio Méliès, hasta que acaba por explotar.

El carácter global del modelo económico inquieta por lo que respecta al colapso. Y es que la globalización impide que las sociedades modernas se derrumben en solitario, como lo hicieron en el pasado la Isla de Pascua y la Groenlandia nórdica (Diamond, 2006, p. 28). Un ejemplo de los efectos de la globalización fue la erupción del volcán Eyjafjallajökull en 2010 en Islandia, 

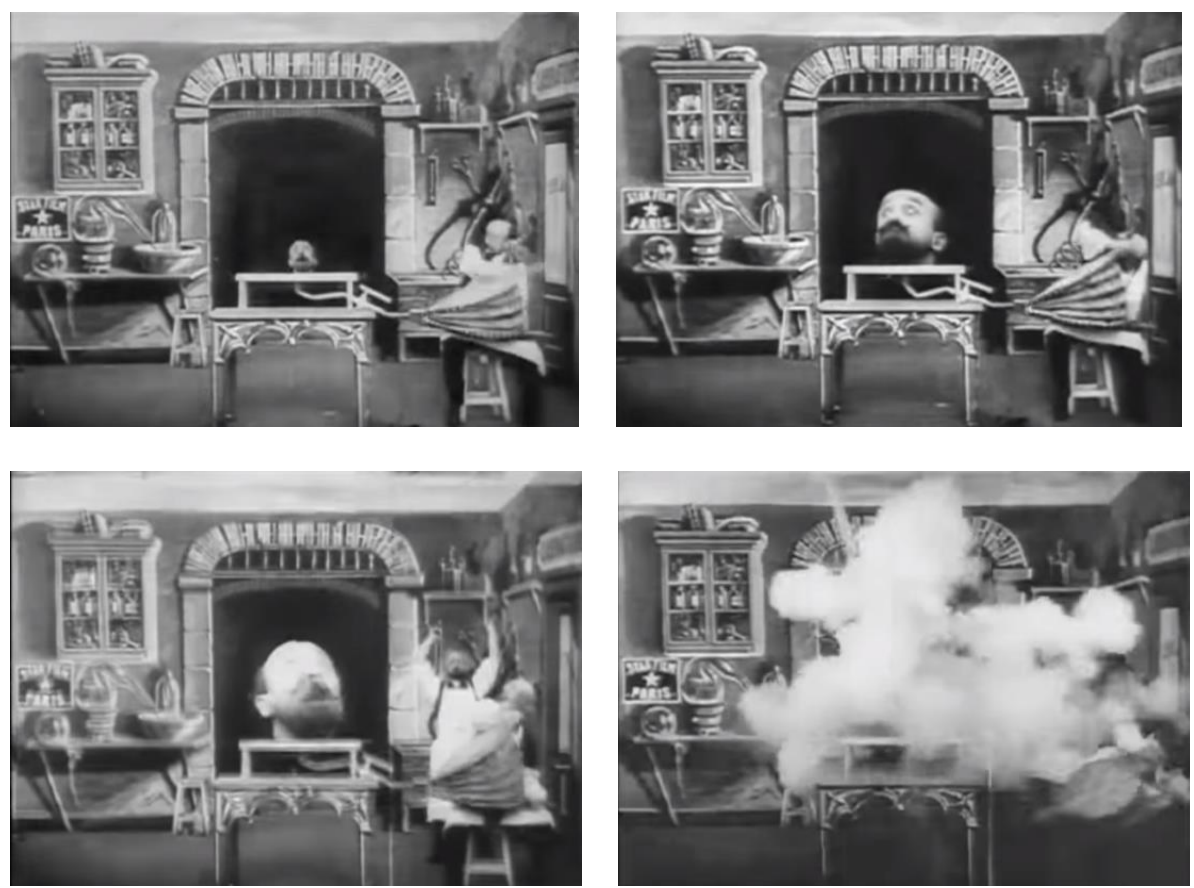

Imagen 3. Georges Méliès. L'homme à la tête en caoutchouc (1901). Fotogramas recuperados de https://www.youtube.com/watch?v=Z01tOEWe7rs 
que causó pérdidas de trabajo en Kenia, hizo que se anulasen operaciones quirúrgicas en Irlanda y provocó la detención de tres líneas de producción de BMW en Alemania (Servigne \& Stevens, 2015, p. 116).

Por otro lado, a diferencia de otros colapsos anteriores, como el de la URSS, en un colapso generalizado será difícil migrar a zonas más estables, o incluso pasar el relevo de la hegemonía a otras sociedades desvinculadas. Por primera vez en la historia nos enfrentamos al riesgo de un declive global.

\section{Pero ¿Qué se Entiende por Colapso?}

Son muchas las definiciones de colapso. La Real Academia de la Lengua Española define colapso, en su primera acepción, como destrucción, ruina de una institución, sistema, estructura, etc. Una definición más afinada sería la que proporciona Cochet, para quien "el colapso es un proceso a la salida del cual las necesidades básicas no se satisfacen para la mayoría de la población" (Taibo, 2016, p. 22). De esta definición se desprende que el colapso es un proceso, es decir que conlleva un tiempo y unas fases, y que no puede ser definido como tal hasta ser completado. Mientras tanto, se tratará de un declive. También resulta llamativo que, para Cochet, el indicador de colapso sea la falta de cobertura de las necesidades básicas para la mayoría de la población. A pesar de lo vago que resulta el concepto de necesidades básicas, es interesante el carácter social del indicador que, curiosamente, también juega un papel protagonista en la definición de sostenibilidad, tal y como veremos más adelante.

Para Tainter, una sociedad ha colapsado "cuando muestra una rápida y significativa pérdida de un nivel establecido de complejidad sociopolítica" (Taibo, 2016, p. 23). Quedémonos, por el momento, con el concepto de cambio de estado de un orden complejo a uno sencillo. En el siguiente apartado se entenderá porqué destacamos esta definición.

\section{Paralelismos entre Arte y el Concepto Geológico de Colapso}

En los últimos años estamos asistiendo a un creciente interés hacia el territorio y en concreto hacia la geografía desde las prácticas artísticas. Tal como nos dice Teresa Blanch: 
El arte reciente se halla comprometido con una nueva medición conceptual del topos. Con sus estrategias está logrando poner a la intemperie las representaciones territoriales del poder, tanto en lo que afecta a lo que vemos como a aquello que se esconde bajo las imágenes dominantes. Y, a su vez, promueve la capacidad actuante del sujeto, para lograr una práctica espacial mucho más afectiva y cercana que invite a las personas a producir momentos, a generar nuevos lugares fuera del consenso, e incluso a construir dialogías que permitan abrir límites de interpretación del espacio. (Blanch, 2015, p.21)

En este sentido, la co-autora de este artículo ha llevado a cabo una investigación artística basada en el paralelismo entre el colapso de las sociedades y los procesos de inestabilidad del terreno que lleva por título Sobre aludes y derrumbres (2017) (véase Imagen 4). Los resultados, resumidos a continuación, se muestran interesantes para profundizar en el evento catastrófico entendido como el momento preciso de cambio, y comprender mejor cada una de las fases que se suceden: del equilibrio inestable al desequilibrio y al posterior equilibrio estable.

$\mathrm{Al}$ establecer dicho paralelismo, surgen dos aspectos que curiosamente encajan con las definiciones de colapso de las sociedades. El primero es el hecho de que el factor desencadenante del desprendimiento sea la falta de cohesión. Desde el punto de vista geológico, el colapso se produce cuando las partículas del suelo (o roca) no están cohesionadas entre sí y presentan huecos, de manera que ofrecen poca resistencia en comparación con las tensiones que soportan (Iriondo, 2007, p. 85). Entonces, el suelo (o roca) se vuelve inestable y acaba por caer, en forma de deslizamiento, derrumbe, avalancha, flujo de barro, hundimiento, etc. De la misma manera, como si de un alud, derrumbe o hundimiento se tratara, es también la falta de cohesión entre los elementos de las sociedades un factor desestabilizante que puede provocar su caída ${ }^{1}$. Recordando la definición de Cochet, es la debilidad de la 


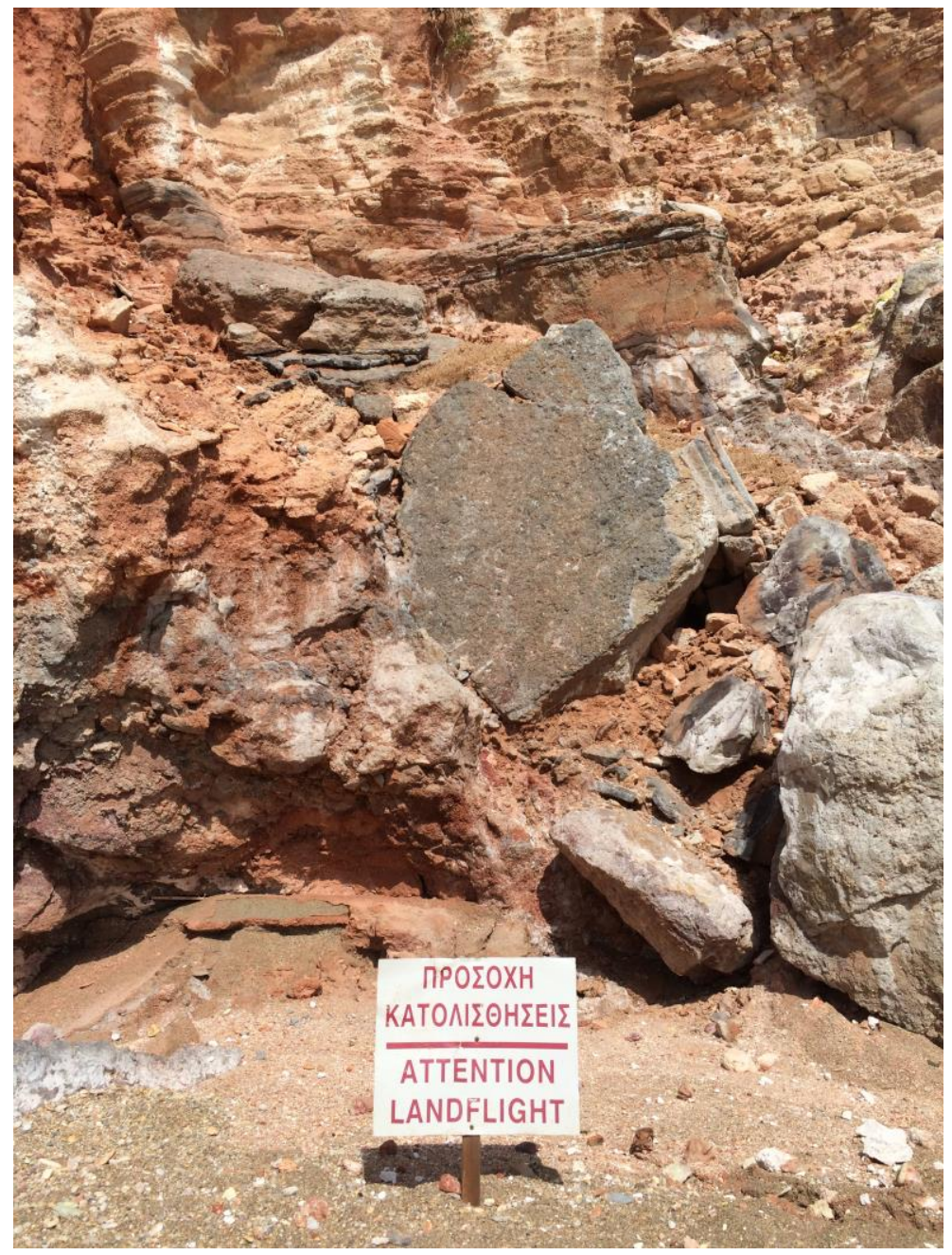

Imagen 4. Paula Bruna. Sobre aludes y derrumbes (2017). Fuente propia. 
mayoría (por debajo de unos mínimos, los de las necesidades básicas) lo que define el colapso (Taibo, 2016, p. 22). Y una sociedad débil deriva, inevitablemente, en una sociedad poco cohesionada.

La segunda curiosidad es que, tanto para las sociedades como para los suelos, el colapso rompe el sistema u orden establecido, y tras la caída se produce un nuevo orden menos complejo que el anterior. Esto concuerda con la definición de Tainter, expuesta anteriormente, para quien la pérdida de complejidad rápida y significativa demuestra que una sociedad ha colapsado (Taibo, 2016, p. 23). Cabe resaltar que, tras el colapso, el nuevo orden es más estable que el anterior, y genera nuevos acontecimientos en el sistema. Por tanto, el uso metafórico de los aludes, avalanchas, derrumbes y otros movimientos de masa para referirse al declive y colapso de las sociedades resulta adecuado e interesante por sus paralelismos. Y como, de acuerdo con lo expuesto anteriormente, no podemos asegurar que se está produciendo un hundimiento hasta que el proceso acabe, se puede decir que, por el momento, vemos piedras caer.

Precisamente, la atención prestada a las piedras, y en general a la geología, ha crecido exponencialmente en las últimas décadas en el campo de la investigación artística. Recientes proyectos artísticos han escogido los deslizamientos y avalanchas para aproximarse a conflictos ambientales y sociales. En Sobre glaciares y avalanchas (2015-2016), Irene Kopelman lleva a cabo una investigación sobre el fenómeno de los glaciares desde el estudio del comportamiento de la naturaleza y la reflexión sobre el deshielo de éstos como consecuencias del cambio climático. Por su parte, Sara Ramo ha utilizado frecuentemente las avalanchas para tratar el tema del consumismo, como en Tiempo de avalancha (2005) (véase Imagen 5) y Lo que nos echen (2012). Como último ejemplo, en Descampados, demoliciones y ruinas (2013) (véase Imagen 6), Lara Almarcegui "focaliza $\mathrm{su}$ atención hacia aquellos lugares (...) y estructuras en proceso de transformación, en los que propone proyectos de intervención que cuestionan el modelo urbanístico global y le sirven para excavar en la identidad de los lugares a través de su fisicidad" (Viladomiu, 2015, p.28). En esta obra presentada en el Pabellón español de la 55 $5^{\mathrm{a}}$ Bienal de Venecia, Almarcegui utiliza la estética del derrumbe para analizar los procesos de 


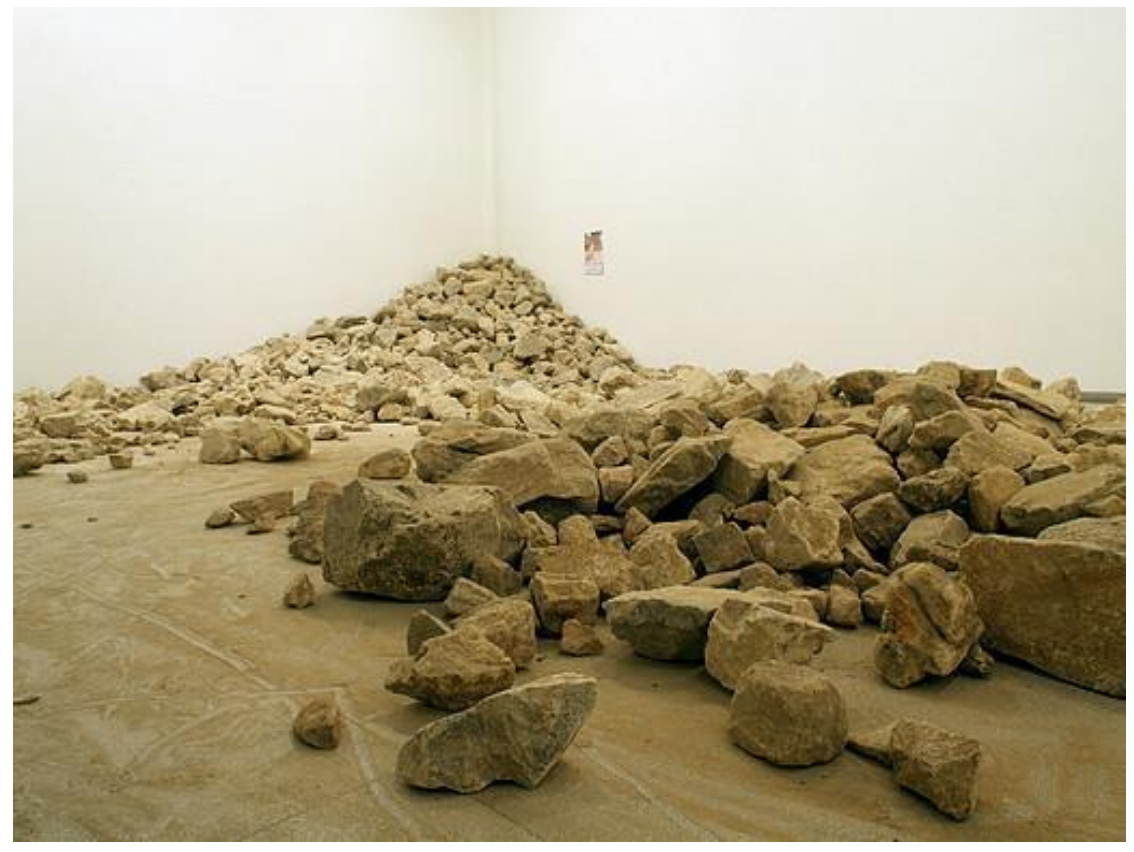

Imagen 5. Sara Ramo. Tiempo de avalancha (2005). Recuperada de http://limac.org/collection/limac-collection/sara-ramo/works/avalanche-time/ 


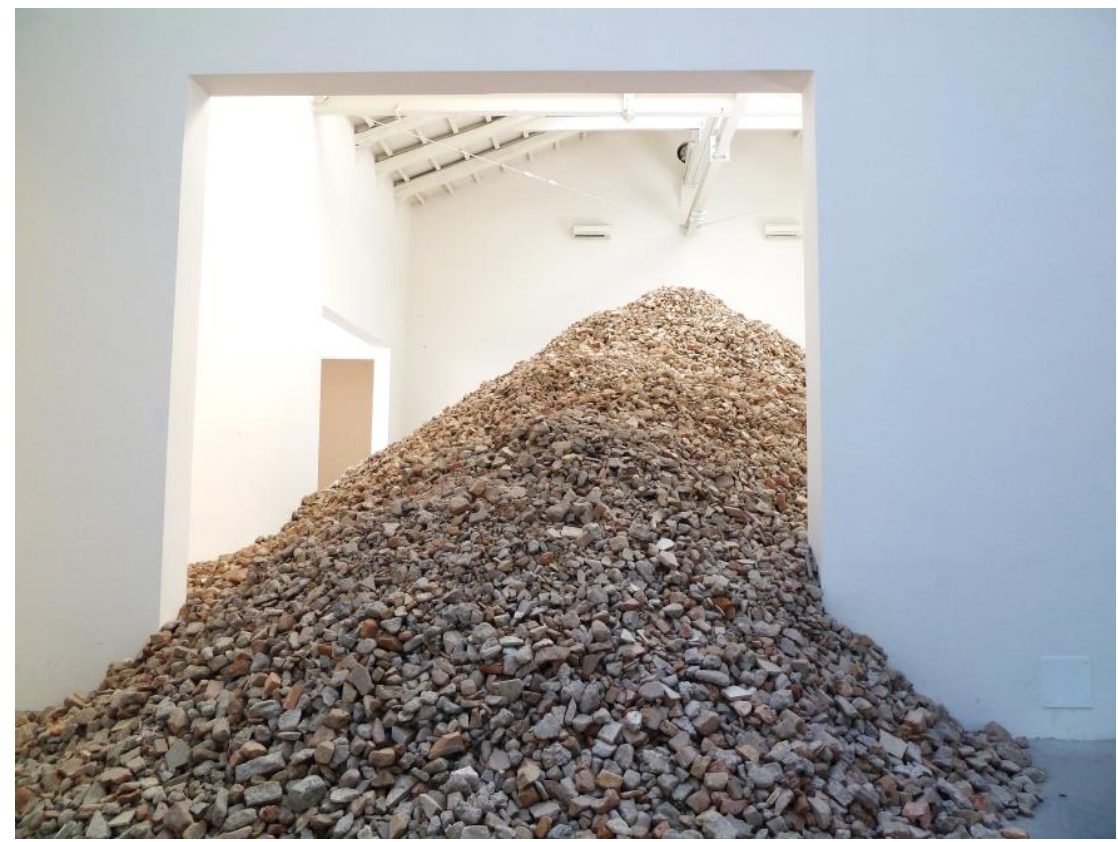

Imagen 6. Lara Almarcegui. Descampados, demoliciones y ruinas (2013). Pabellón de España, 55 a Bienal de Venecia. Fuente propia. 
construcción y deconstrucción de los edificios, aportando un punto de vista crítico hacia los excesos de la construcción.

(...) este proyecto lo he realizado varias veces y quiero seguir realizándolo, porque no estamos hablando ya de un experimento más o menos artístico, sino que (...) estamos hablando de pelearse contra la construcción y el diseño y mientras pueda tengo que hacerlo, casi por obligación". (Almarcegui, 2015, p.49)

\section{Tipos de Respuestas ante el Colapso y su Interpretación en el Arte Contemporáneo}

Ante los argumentos sobre el posible hundimiento del sistema, se dan diferentes tipos de respuestas, que agruparemos en tres.

\section{Respuestas del Tipo 1: El Statu Quo del Crecimiento Sostenido}

El primer grupo de respuestas ante el colapso tiene en común la inacción. Bien por desconocimiento, bien por la no aceptación del riesgo, o bien por la priorización de intereses privados, aún son muchos los que defienden las bondades del modelo de crecimiento sostenido. En todo caso, cuando conviene, recurren al greenwashing, soluciones meramente cosméticas para camuflar como sostenibles decisiones difícilmente aceptables o con el fin de aumentar las ventas (pues lo verde vende). Este es el caso de las aerolíneas, fabricantes de automóviles, bancos y compañías de energía de combustibles fósiles que patrocinaron las conversaciones de la ONU sobre el clima en París, en 2015, lo que suponía una gran paradoja, dada su elevada contribución en las emisiones de gases de efecto invernadero. Con el objetivo de poner en evidencia este greenwashing, el colectivo de artistas activistas Brandalism instaló 600 carteles por toda la ciudad que denunciaban la utilización del patrocinio de las conversaciones como una forma de comercialización. 


\section{Fase Compartida por las Respuestas del Tipo 2 y 3: El Despertar de la Ecognosis}

El segundo y tercer tipo de respuestas vienen motivadas por la atención hacia los conflictos ecológicos y la concienciación de la existencia de errores en el actual sistema. En una primera fase de esta ecognosis $^{2}$, se despierta una conciencia de las consecuencias de la actividad humana (acumulación de residuos, contaminación...) y una sensibilidad hacia otros componentes de la ecoesfera (bosques, ballenas, osos polares, ríos, tierra...).

Cada vez son más los artistas que están basando sus proyectos en la empatía con los demás habitantes del planeta con la intención de despertar esa sensibilidad, que consideran necesaria para la construcción de un nuevo paradigma ecológico. En el artículo de Albelda \& Sgaramella (2015), se estudiaron las estrategias de creación de empatía adoptadas por los artistas con el fin de potenciar la conciencia ambiental. Entre los proyectos artísticos analizados, se encuentra Plein Air (2006-2010) (véase Imagen 7), de los artistas Tim Collins y Reiko Goto. En este proyecto, los artistas focalizan su investigación en las interacciones entre seres humanos y árboles con la intención de "hacer visible la voz del otro" no humano para impulsar una actitud ética ante la naturaleza (Goto, 2012). Otro ejemplo de construcción de un vínculo empático con el ecosistema es la obra escultórica Human Microbiome (2009) de los artistas italianos Andrea Caretto y Raffaella Spagna, que descubre las relaciones simbióticas entre bacterias y humanos, necesaria para nuestra supervivencia. Por otra parte, algunos proyectos artísticos se han basado en potenciar la otra sensibilidad, la referida a la concienciación hacia los conflictos ecológicos ocasionados por la actividad humana. Brandon Ballengée, por ejemplo, se basa en sus conocimientos como biólogo para componer instalaciones a cerca de aspectos como la pérdida de biodiversidad The Frameworks of Absence (2006) o la sobreexplotación de los recursos pesqueros Collapse (2012) (véase Imagen 8). Por su parte, los icebergs de Olafur Eliasson en Your waist of time (2006) llevan a reflexionar sobre la inacción ante el cambio climático. 


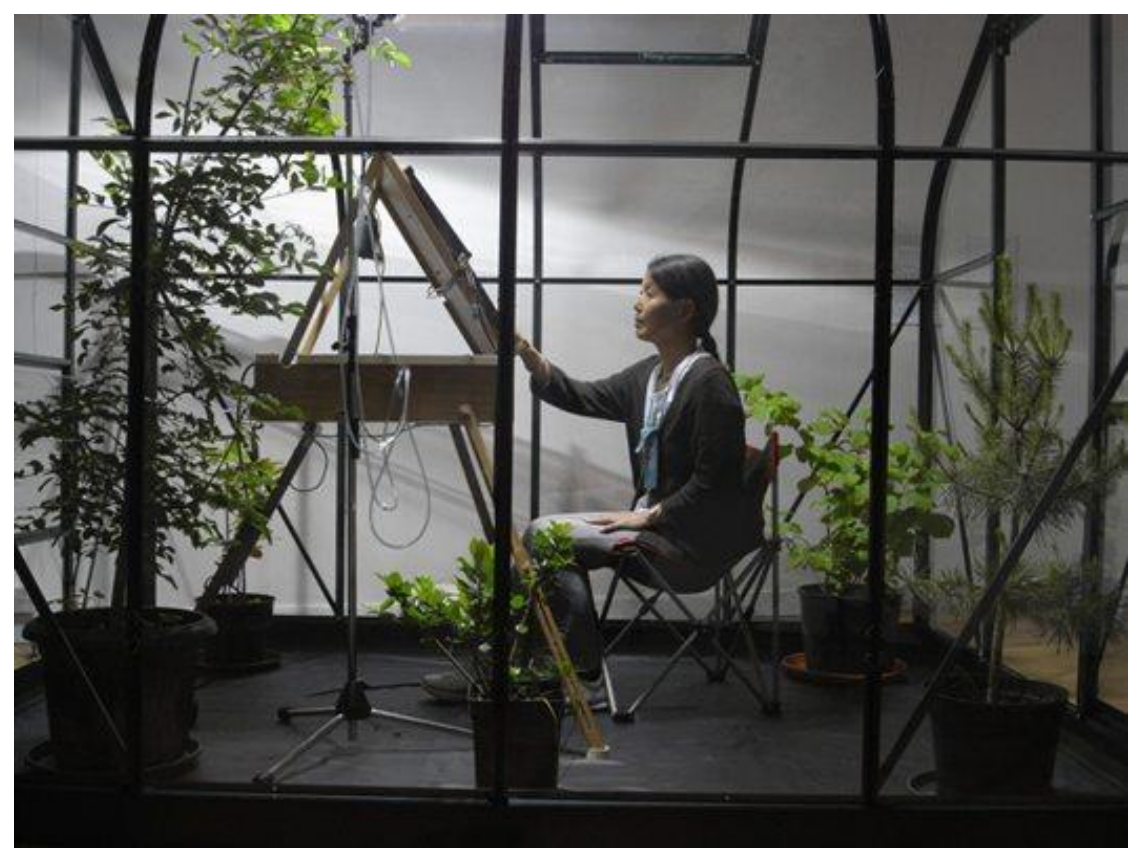

Imagen 7. Tim Collins \& Reiko Goto. Plein Air (2006-2010). Recuperada de https://directory.weadartists.org/scotland-plen-air 


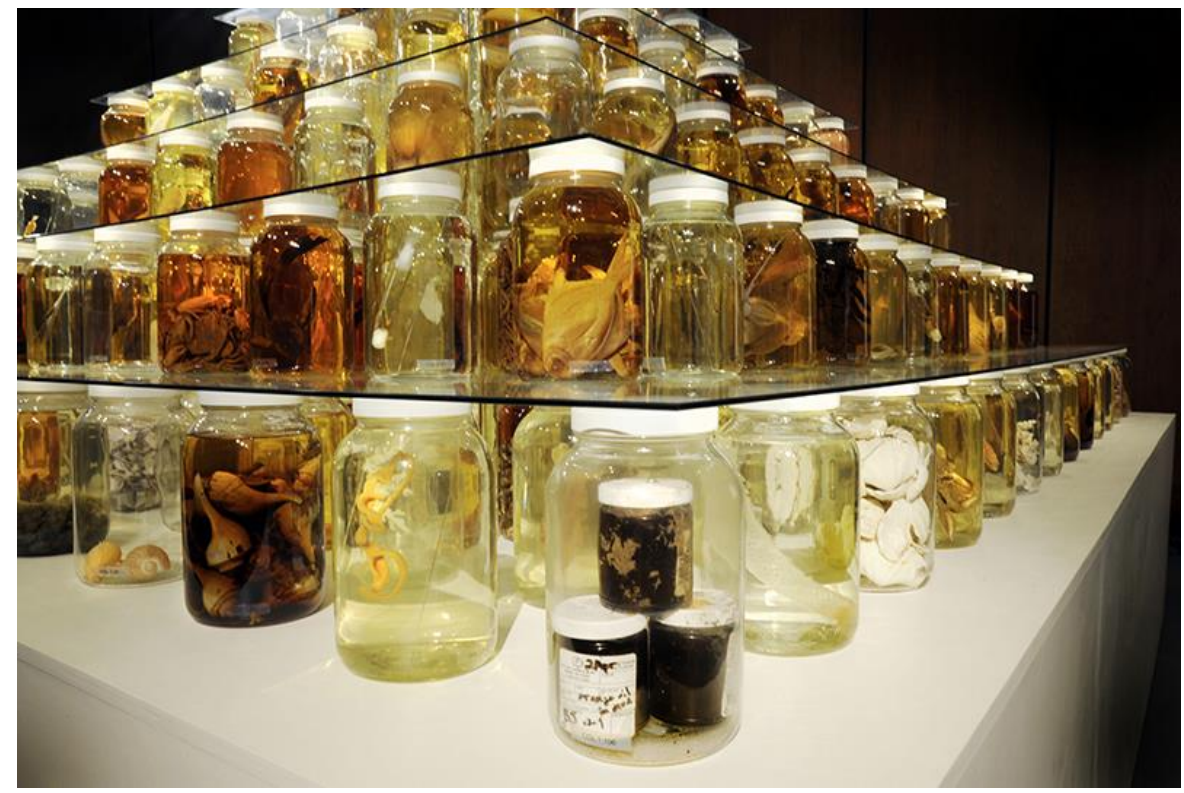

Imagen 8. Brandon Ballengée. Collapse (2012) Recuperada de https://brandonballengee.com/collapse 
Una vez iniciada esta ecognosis y asumido que el sistema socioeconómico actual comporta conflictos ecológicos perjudiciales también para el ser humano, se plantea la necesidad de cambiar hacia un modelo sostenible. Pero ¿qué se entiende por sostenible? La definición más difundida es la que aparece en el informe Brundtland ${ }^{3}$ (CMMAD, 1987), y que determina que el desarrollo (o crecimiento ${ }^{4}$ ) sostenible es aquel que cubre las necesidades del presente sin comprometer la capacidad de las generaciones futuras para cubrir las suyas. En términos económicos, las necesidades de las generaciones se cubren a través del capital. Por tanto, el desarrollo sostenible sólo se logra si la sociedad de hoy lega a las personas del futuro un stock de capital igual o superior al que usa en el presente. A partir de aquí, se bifurcan dos versiones de sostenibilidad, cuya diferencia es muy relevante, y que corresponden con el segundo y el tercer tipo de respuestas ante el colapso.

\section{Respuestas del tipo 2. Hacia el crecimiento sostenible: hacer compatible el crecimiento económico con la sostenibilidad}

El segundo tipo de respuestas ante el colapso lo protagonizan los partidarios de la sostenibilidad débil. Para ellos, el modelo a seguir es el del crecimiento sostenible, y se justifica argumentando que es posible seguir creciendo sin poner en riesgo las necesidades de las generaciones futuras a costa de sustituir capital natural por capital tecnológico (Luffiego \& Rabadán, 2000, p. 475). El concepto de sostenibilidad débil está fuertemente fundamentado en la fe en la tecnología (Pérez Adán, 1997, citado en Luffiego \& Rabadán, 2000 , p. 475), y se basa en la creencia de que el mismo sistema es quien aportará las soluciones. Cabe decir que los principios de la sostenibilidad débil son los que guían las políticas internacionales sobre biodiversidad y cambio climático (entre ellos, el último acuerdo de París COP21 para frenar el calentamiento global) y las administraciones ambientales. Por ejemplo, entre los objetivos de desarrollo sostenible de la ONU se encuentra el de "promover el crecimiento económico sostenido, inclusivo y sostenible, el empleo pleno y productivo y el trabajo decente para todos" (ONU, 2015). Es 
decir, que la ONU parte de la premisa de que el crecimiento sostenido puede ser sostenible, ergo se rige por los principios de sostenibilidad débil.

En un primer análisis, descubrimos algunos proyectos artísticos que responden a los principios de la sostenibilidad débil. En general, se trata de proyectos que apuestan por soluciones ingenieriles para reducir el impacto ambiental, sin que suponga alterar significativamente el modelo de crecimiento económico actual. En el proyecto Tree x Office (2012) (véase Imagen 9), Natalie Jeremijenko crea un espacio de trabajo en un árbol urbano, con el objetivo de cambiar el entorno artificial de las oficinas por uno natural. El espacio, construido con materiales respetuosos con el medio ambiente, estaba dotado de la tecnología necesaria para ofrecer electricidad (mediante placas solares) y WiFi, y era alquilado como espacio de trabajo a las empresas interesadas. Se trata, pues, de una apuesta interesante por cambiar la forma, pero no el fondo del sistema.

Por otra parte, en la instalación Hylozoic Soil (2007) Philip Beesley utiliza los recursos de la robótica para emular la vida de un bosque, en lo que sería un ejemplo de sustitución de capital natural por capital tecnológico. Este proyecto da pie al debate sobre los límites de la tecnificación del capital natural, que quedan reflejados en el ejemplo del economista ecológico Herman Daly:

La fibra de algodón puede ser sustituida por la fibra sintética para la fabricación de ropa y una plantilla de cien trabajadores puede ser sustituida en parte por tecnología o viceversa, (...) [pero] numerosos y modernos aserraderos no podrían sustituir la escasez de madera si ésta se acabase o la mejor flota pesquera sería incapaz de sustituir los caladeros agotados (...). (Daly, 1992, citado en Luffiego y Rabadán, 2000, p. 475) 


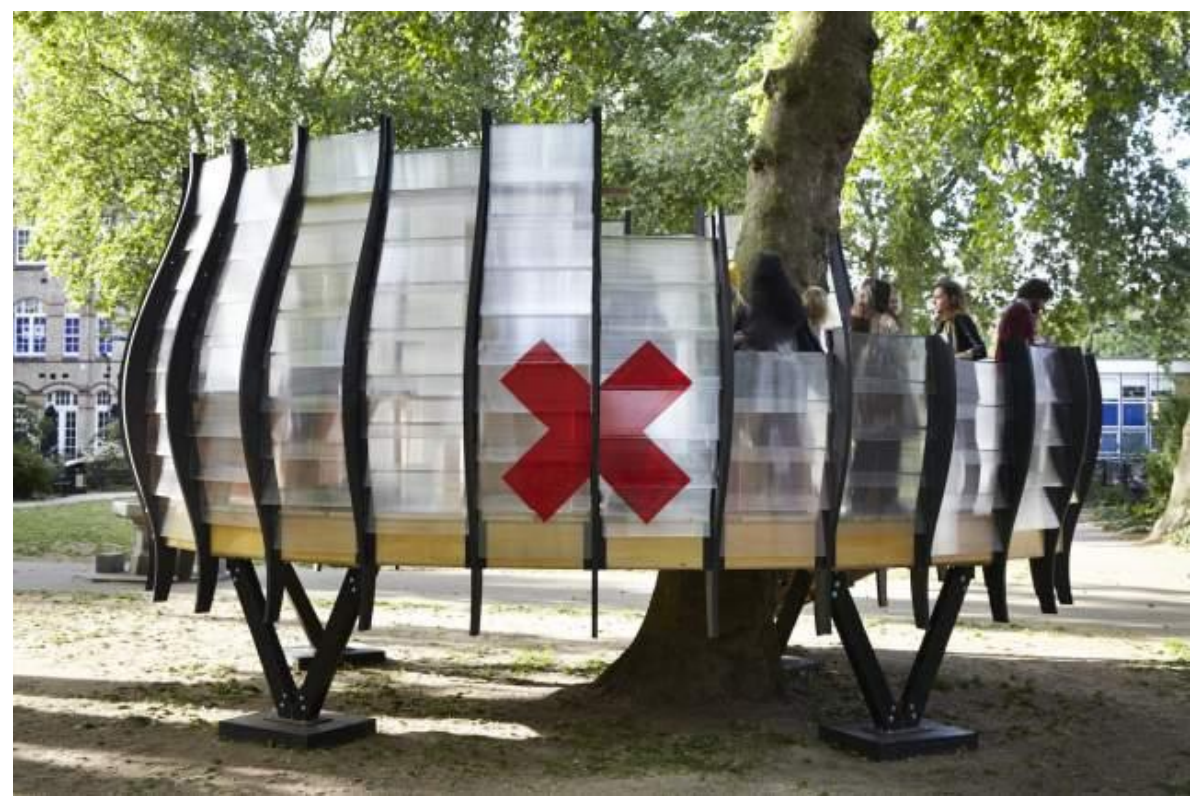

Imagen 9. Natalie Jeremijenko. TREExOFFICE (2012). Recuperada de https://www.artsadmin.co.uk/projects/natalie-jeremijenko-treexoffice 
El tercer proyecto que relacionamos a la corriente de sostenibilidad débil es la instalación Exceeding $2{ }^{\circ} \mathrm{C}$ (2007-2014) (véase Imagen 10), de Tue Greenfort, que presentó por primera vez en la Bienal de Sharjah Art de los Emiratos Árabes Unidos titulada Still Life: Art, Ecology and Politics of change (2007). Este proyecto consistió en incrementar en $2^{\circ} \mathrm{C}$ la temperatura del museo (regulada mediante aire acondicionado) durante todo el tiempo de la exposición. La subida de la temperatura del termostato conllevó un ahorro energético, y el dinero ahorrado se destinó a la mejora de un bosque tropical en Ecuador. Está claro que la reducción del consumo energético comporta ventajas ambientales en cuanto a consumo de recursos, gestión de residuos peligrosos, y emisiones de contaminantes y gases de efecto invernadero. Sin embargo, un escenario más sostenible que el anterior no es necesariamente un escenario sostenible. Y es que, tal y como apunta el concepto de jerarquía de mitigación (concepto de la evaluación de impactos que establece la aplicación de los siguientes pasos en orden estricto: evitar, minimizar, restaurar, compensar) (Mitchell, 1997), el no impacto es siempre mejor que cualquier impacto.

\section{Respuestas del tipo 3: Hacia el desarrollo sostenible: cambiar a un sistema socioeconómico adaptado al sistema ecológico}

Por último, llegamos al tercer tipo de respuestas, que corresponde a los partidarios de la sostenibilidad fuerte. Éstos argumentan que, dado que cierto tipo de recursos naturales no pueden ser reemplazados por la tecnología, "crecimiento" y "sostenible" devienen incompatibles. La apuesta es, entonces, por el desarrollo sostenible: la economía debe sustituir el concepto de crecimiento (=cantidad) por el de desarrollo (=calidad) y ajustarse al contexto ecológico (Daly, 1997).

De esta manera, mientras la sostenibilidad débil propone ajustes del modelo económico y social en aras del crecimiento sostenible, la sostenibilidad fuerte defiende que éstos no son suficientes, de la misma forma que, por mucho que se reduzca la dosis de un veneno, si ésta sigue siendo letal, la víctima no se salvará. Únicamente un cambio profundo en el modelo económico y social actual puede evitar el colapso de la civilización (Latouche \& Harpagès, 2011). Y este cambio comienza a ser urgente. 


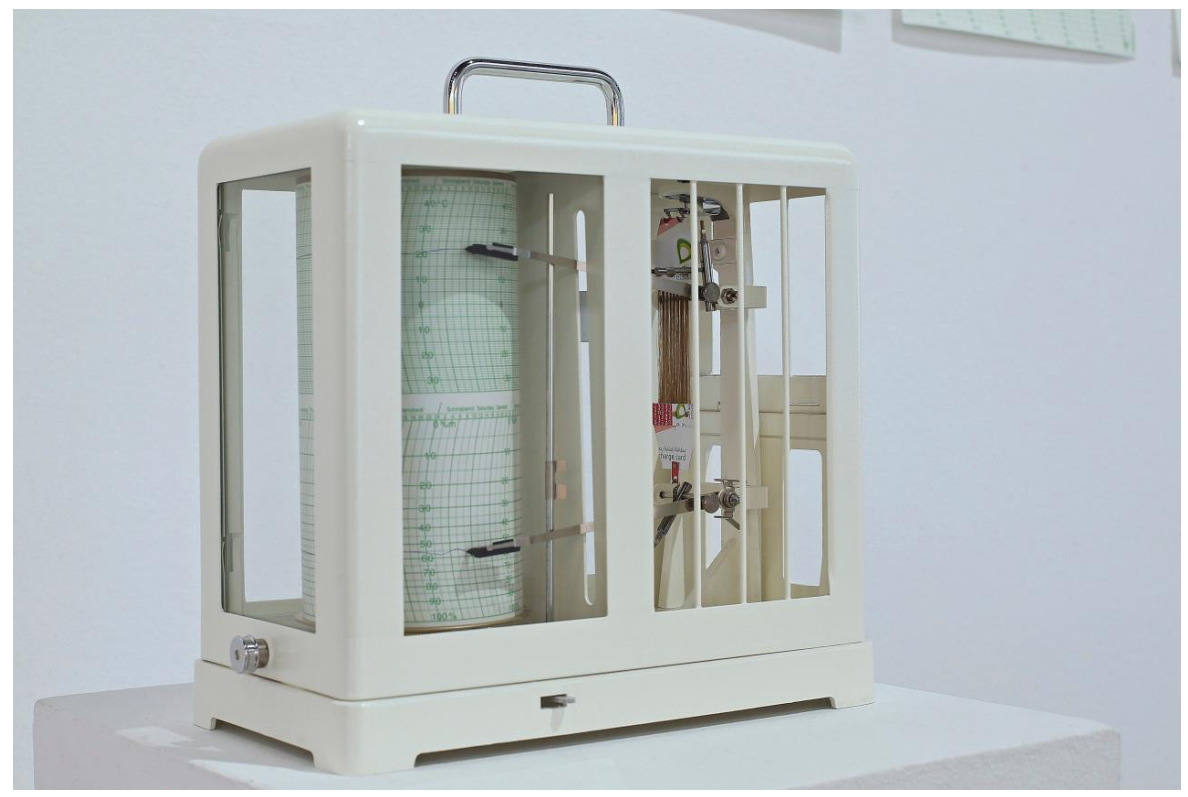

Imagen 10. Tue Greenfort. Exceeding $2{ }^{\circ} \mathrm{C}$ (2007-2014). Recuperada de http://tuegre enfort.net/post/79156310983/exceeding-2-c-20072014-still-life-art-ecology 
En consecuencia, las propuestas artísticas relacionadas con los principios de sostenibilidad fuerte están fundamentadas en profundos cambios del sistema socioeconómico actual. Quizás sea por eso que es más fácil encontrar ejemplos en el activismo artístico. El grupo EZLN (Ensemble Zoologique de Libération de la Nature) ha llevado a cabo diversas acciones bajo el slogan We are nature defending itself ${ }^{5}$. Este slogan cuestiona la separación entre lo natural y lo artificial, y alude a la integración de la especie humana en la compleja estructura del ecosistema al mismo nivel que las demás especies. Este planteamiento concuerda con lo señalado por Daly, economista defensor de la sostenibilidad fuerte: "La economía es un subsistema de la biosfera, y no un sistema independiente" (Taibo, 2016, p. 17).

El proyecto Yomango (2002-2006) (véase Imagen 11) es otro ejemplo de activismo artístico que responde a la necesidad de cambio socioeconómico que plantea la sostenibilidad fuerte. Este grupo propuso una serie de acciones de reivindicación en contra del capitalismo y el consumismo, utilizando como dispositivo el robo. Su artivismo se basa en un tipo de reivindicación lúdica, de manera que el boicot a la espiral de producción y consumo se plantea desde la fiesta y el disfrute: desactivar el placer del consumo mediante el placer que proporciona el acto de robar.

El colectivo Adbusters proclama en sus principios que el sistema económico neoclásico comporta desastres sociales y ecológicos, y aboga por construir un sistema radicalmente nuevo, haciendo referencia a una famosa cita del economista Robert Heilbroner: "antes de que la economía pueda progresar, ésta debe abandonar su formalismo suicida" (Heilbroner, citado en Lasn y Fleet, 2011). Esta organización utiliza la publicidad como un medio de comunicación de sus ideas, y de lucha contra el consumismo. El diseño Name these brands, name these plants (2012) (véase Imagen 12) supone un golpe de realidad ante las prioridades del sistema socioeconómico en el que estamos inmersos, e invita a una autoreflexión acerca de la desvinculación del sistema ecológico del cual dependemos. 
BRAC-Barcelona Research Art Creation, 6(2)

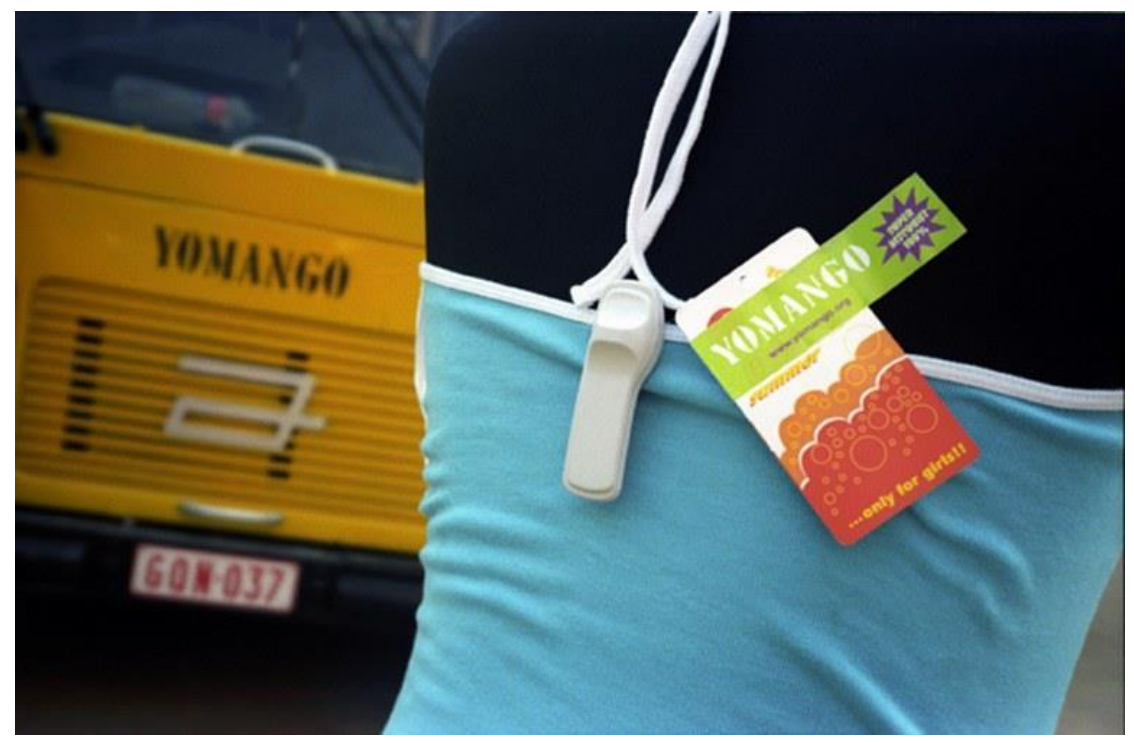

Imagen 11. Yomango. Presentación de la marca (2002-2006). Fuente: imagen cedida por los artistas. 
Name these brands

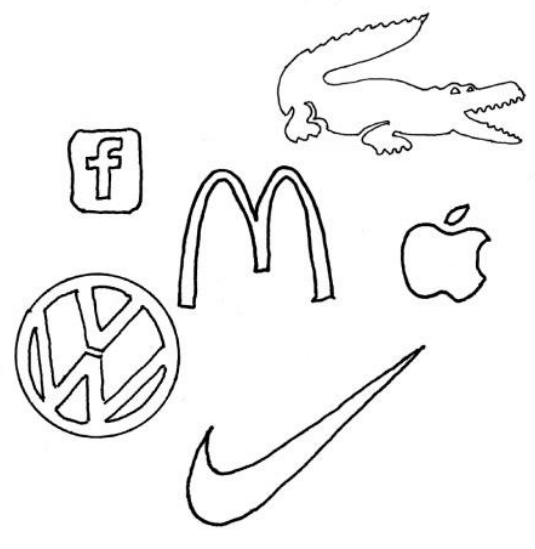

Name these plants

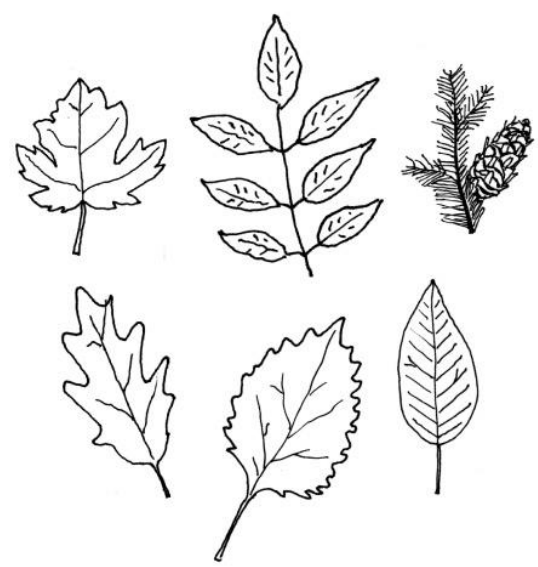

Imagen 12. Adbusters. Name these brands, name these plants (2012).

Recuperada de http://www.adbusters.org/spoofads/environmental/ 
Fuera del artivismo también se encuentran propuestas artísticas que se alinean con los principios de sostenibilidad fuerte. Los planteamientos de trabajo del artista Andy Goldsworthy implican un avanzado grado de ecognosis, y van desde la plena integración del hombre en la naturaleza, hasta el respeto del tiempo, el volumen, el material y las condiciones climáticas del ambiente donde realiza sus obras, lo que le convierte en un ejemplo de máxima adaptación al entorno:

La sensación de que hay una división entre nosotros y la naturaleza no es verdadera. Somos naturaleza. Es un peligro vernos a nosotros mismos como cualquier otra cosa. Necesitamos ser conscientes de nuestras conexiones con la tierra. (Goldsworthy, citado en Wade, 2017).

Quiero una relación físicamente íntima con la tierra. Debo tocar. No llevo nada conmigo en cuanto a herramientas, pegamento o cuerda, y prefiero explorar los lazos naturales y las tensiones que existen dentro de la tierra. Las estaciones y las condiciones climáticas determinan en gran medida lo que hago. Disfruto confiando en las estaciones para proporcionar nuevos materiales. (Goldsworthy, 1980)

En España, destacamos el proyecto Campo Adentro, una iniciativa coordinada por el artista Fernando García-Dory, que proporcionaba una plataforma de diálogo entre artistas, agricultores, administradores y agentes culturales activos en contextos urbanos y rurales. El medio rural es el escenario protagonista y agente dinamizador para la generación de diversas formas de vida que difieren del modelo hegemónico. Tal y como expone su manifiesto, el proyecto "pretende confrontar varios problemas que se relacionan simultáneamente - la insostenibilidad ambiental, cultural y económica de un modelo en quiebra, tanto a escala global como individual formulando herramientas teóricas de análisis crítico y aplicándolas en la práctica experimental.” (García-Dory, s.f., recuperado en http://www.inland.org) 
Por otra parte, las propuestas de Pierre Huyghe suponen un cambio de paradigma en el planteamiento de nuevos futuros. En Untilled (2011-2012), el insólito jardín que Huyghe creó en el Karlsaue Park de Kassel durante la dOCUMENTA 13, el artista partió de un espacio abierto dedicado al almacenaje y compostaje e incorporó elementos (organismos vivos y objetos). Éstos se desarrollaron en procesos independientes liberados del tiempo antropocéntrico. El propio artista lo define como "un lugar donde las cosas abandonadas sin cultura se vuelven indiferentes a nuestra mirada, se metabolizan y permiten la emergencia de nuevas formas" (Huyghe, 2012, citado en Speranza, 2017). Así, el punto de partida es el deshecho, o en el contexto de este artículo, un escenario de postcolapso. Un colapso que ha comportado una estructura simplificada pero que no es un final, sino como ya hemos dicho, el cambio de orden necesario para que sucedan otras cosas. En Untilled (véase Imagen 13) las cosas acontecen indiferentes a nosotros, fuera de nuestro sistema, y de nuestro egocentrismo, en lo que Enrique VilaMatas describe como "clima de extrema rareza" (Vila-Matas, 2014, citado en Speranza, 2017). La apuesta por algo raro (es decir, fuera de lo que en nuestro entorno consideramos como normal), ajeno a nuestro sistema de necesidades y servicios, y fuera de nuestra escala temporal, es quizás el tipo de propuestas que abre puertas hacia esos nuevos futuros que necesitamos plantearnos. La visión ecosistémica y de red compleja intrínseca en la obra de Huyghe resulta muy interesante, ya que no se plantea como un espejo del pasado sino como desarrollador de un futuro incierto.

\section{El decrecimiento, una variante de la sostenibilidad fuerte}

De los principios de sostenibilidad fuerte surge una variante, la teoría del decrecimiento, que advierte de la necesidad de alejarse del crecimiento del consumo como finalidad para poder vivir mejor. Este movimiento, surgido en los años setenta, afirma que los límites de la sostenibilidad ya se han rebasado. Para obtener una huella ecológica "correcta" (un solo planeta) debería reducirse en un $30 \%$ las extracciones de recursos naturales, lo que se podría obtener gracias a una disminución del $50 \%$ del consumo final 


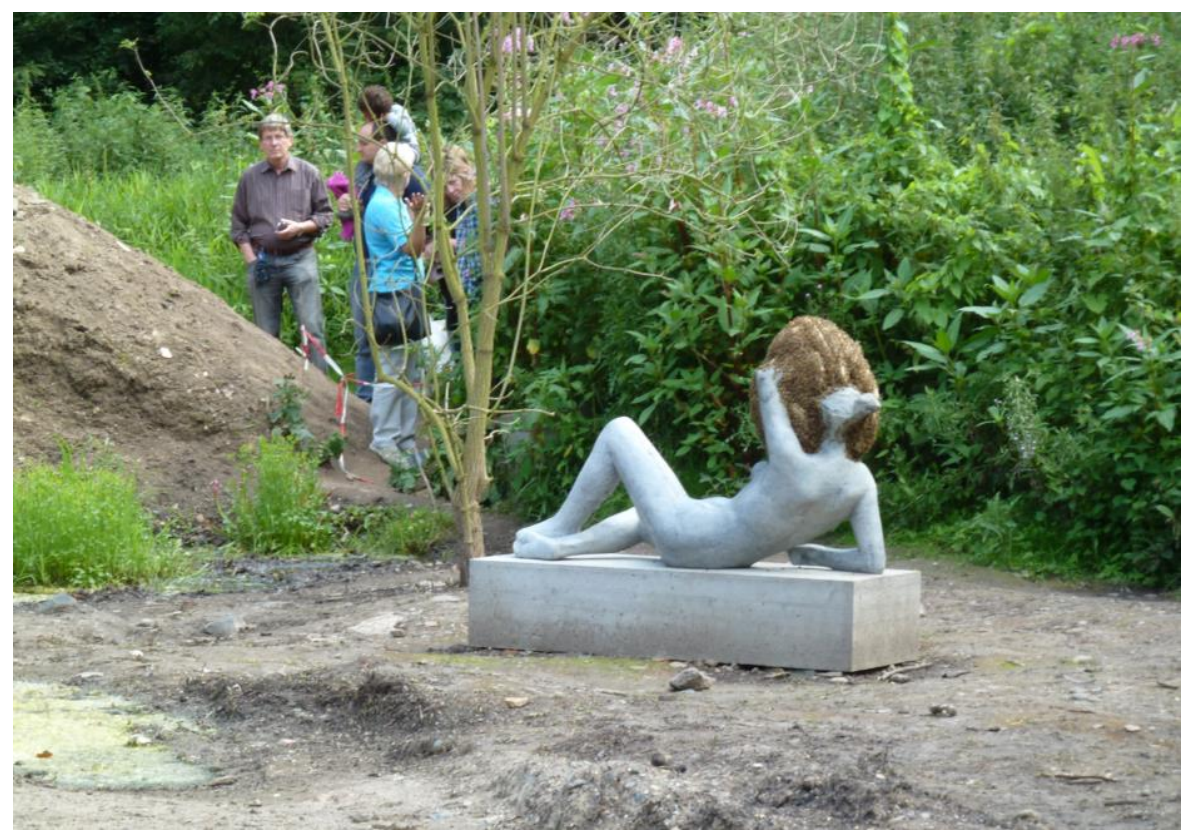

Imagen 13. Huyghe. Untilled (2011-2012). Fuente propia. 
(Latouche, 2009, p. 56). Esta reducción, llevada a cabo de manera consentida, no conduciría a una crisis económica, y tampoco significaría una regresión al pasado, sino que conduciría a un nuevo futuro, el único en el que, según los partidarios de este movimiento, es posible un incremento de la calidad de vida. Uno de sus máximos exponentes, Serge Latouche, expone que el decrecimiento supone "trabajar menos para vivir mejor, consumir menos pero mejor, producir menos residuos, reciclar más... En pocas palabras, recobrar el sentido de la mesura y una huella ecológica sostenible", y para ello, es necesaria "una ruptura de nuestros hábitos y por lo tanto de nuestras creencias y nuestras mentalidades" (Latouche y Harpagès, 2011, p. 16).

En el campo del arte y la arquitectura, las teorías del decrecimiento toman la forma de la no construcción y la deconstrucción. Así, en los últimos años se han alzado voces que, ante la construcción desatada y la desvinculación de los proyectos constructivos y urbanísticos de las necesidades sociales, reivindican la intervención en el territorio y la ciudad desde la no construcción, la minimización, la reutilización y el desmantelamiento. Es el caso de N'undo, una plataforma transversal e interdisciplinar de arquitectos, urbanistas, etc., que invita a la acción, extensible también a todas las áreas vitales:

No se trata del menos es más, sino del nada es más, de valorar la ausencia y la preexistencia, por encima de la construcción y lo material; reparar, limpiar y recuperar para mejorar paisaje, territorio y ciudad desde la creación y conservación de sus vacíos y silencios. Actuar mediante la no construcción de propuestas o intervenciones no pertinentes; la reutilización de infraestructuras y edificaciones; la minimización de elementos de impacto nocivo y el desmantelamiento de elementos perniciosos o prescindibles. (N'undo, 2011, recuperado de http://www.nundo.org/) 
Asimismo, la iniciativa Removing Freeways - Restoring Cities de The Preservation Institute (Berkeley, EE.UU.) se centra directamente en el desmantelamiento de autopistas obsoletas, argumentando que resulta más barato que la reconstrucción, y que además incentiva una movilidad más sostenible y una revalorización de las propiedades de la zona. Sostienen que la construcción desmesurada en EE.UU. de avenidas y autopistas urbanas para apaciguar el tráfico fue un error que trajo el efecto contrario, pues el incremento de la oferta supuso un incremento de la demanda. La construcción de autopistas anima a la gente a conducir distancias más largas: en el corto plazo, la gente comienza a conducir a los centros comerciales regionales en lugar de las tiendas locales, y en el largo plazo, se trasladan a los barrios de menor densidad en los que tienen que conducir más lejos para todos sus viajes. Esto conlleva un coste en tiempo, en dinero y en recursos, y un descenso de la calidad de vida (Norquist, 2000). Por ello, esperan que derribando las autopistas y disminuyendo la velocidad se reduzcan las distancias que recorren las personas. El Instituto expone diferentes casos de autovías deconstruidas en estados como San Francisco, Portland, New York, o Milwaukee.

\section{Conclusiones}

Hay indicios suficientes para pensar que el sistema socioeconómico actual basado en el crecimiento ilimitado está colapsando. Las señales de colapso indican que ya no valen las compartimentaciones, y que no puede separarse la crisis ecológica del sistema económico, político y social. El problema es, pues, sistémico, y por tanto el tratamiento también lo debe ser. En consecuencia, el arte ecológico ya no se circunscribe a lo natural o a lo ambiental, sino que pasa por formas y conceptos mucho más amplios.

El paralelismo entre el colapso de las sociedades y los procesos de inestabilidad del terreno resulta interesante, y permite estudiar estos procesos desde otro ángulo. No en vano, las analogías con los 
elementos y procesos geológicos es un recurso que ha crecido exponencialmente en las últimas décadas en el campo de la investigación artística. En ambos tipos de colapso, el geológico y el de las sociedades, la falta de cohesión es un factor desencadenante del desprendimiento. Igualmente, en ambos procesos, tras la caída se produce un nuevo orden menos complejo que el anterior. Sin embargo, del estudio de los procesos geológicos se extrae una nueva manera de entender el colapso, y es como acontecimiento necesario para pasar de un equilibrio inestable o uno estable. Así, el suceso catastrófico también puede ser considerado un suceso creador de nuevas formas, nuevos equilibrios, nuevos sistemas. En todo caso, de momento vemos piedras caer, ya que las definiciones de colapso analizadas implican que no podamos asegurar que se está produciendo un hundimiento hasta que el proceso acabe, aunque sí puede predecirse.

A nivel ecológico, numerosos indicadores alertan de que nos acercamos a límites peligrosos para el mantenimiento de nuestras sociedades. Por citar uno de ellos, la apropiación humana de la producción primaria neta de biomasa señala que la especie humana se apodera de cerca del $40 \%$ de todo lo que producen los ecosistemas terrestres, dejando el $60 \%$ restante para todas las demás especies silvestres del planeta (Vitousek, 1986, citado en Martínez Alier \& Roca Jusment, 2013). Esto no nos viene de nuevo, pues hace casi 50 años que se reconoce institucionalmente la insostenibilidad del sistema. Desde entonces, la situación se ha agravado. Y el cambio no se produce, ni siquiera el que viene de las propuestas más débiles.

Las prácticas artísticas tienen una importante función en el cambio del modelo social. En las revoluciones culturales del siglo pasado, el difuminado de las fronteras entre arte y vida contribuyó a modificar los patrones culturales hegemónicos, transformando la sociedad de manera significativa y asentando nuevos derechos y comportamientos anteriormente prohibidos o marginados (Granés, 2011). En la actualidad, el gran reto de nuestra sociedad es seguramente el tránsito hacia modelos sostenibles, y éste necesita de creatividad e imaginación. Como argumenta Demos (2013, p. 16), se requiere un inmenso proyecto 
de pensamiento y práctica imaginativa para rescatar la naturaleza del control corporativo, financiero y de la explotación del capitalismo, en el que es necesario involucrar artistas, activistas y profesionales creativos (además de científicos, políticos y políticos) en cada etapa. Su potencial para transmitir conocimiento mediante la empatía y la vivencia hacen del arte el complemento necesario de otras disciplinas, y el catalizador para el cambio.

Partiendo del gran abanico de propuestas eco-artísticas, se hace imprescindible discernir aquellas con mayor potencial para el cambio hacia un modelo verdaderamente sostenible. Hay que tener en cuenta que los economistas ecológicos advierten de que el crecimiento económico no puede ser sostenible, y que es imprescindible adoptar un modelo desvinculado del crecimiento y adaptado al contexto ecológico. En consecuencia, el primer paso es diferenciar las prácticas artísticas asentadas en el discurso institucional de sostenibilidad débil de aquellas que se enmarcan en las propuestas de cambio sustancial de la sostenibilidad fuerte y el decrecimiento. Este ejercicio no está exento de dificultades, pues a veces requiere de un conocimiento profundo de la intencionalidad del artista para poder diferenciar con claridad las propuestas que responden al tipo 2, de sostenibilidad débil, de las del tipo 3, de sostenibilidad fuerte. En la mayoría de los casos, los artistas no contemplan adscribirse a un tipo de sostenibilidad determinada. Además, la frontera entre las dos sostenibilidades puede ser difusa, especialmente en la fase compartida de la ecognosis y en determinadas escalas espaciales o temporales. A pesar de ello, es posible identificar propuestas artísticas para cada uno de los dos tipos de sostenibilidad. En la hoja de ruta hacia una sociedad sostenible, sería deseable que la infraestructura artística apostara por potenciar las respuestas del tipo 3 desde un enfoque sistémico y exhaustivo, en lugar de organizar eventos artísticos que responden a problemáticas parciales afrontadas desde planteamientos institucionales, modas, o conceptos bandera (nos referimos, por ejemplo, al auge de las exposiciones artísticas entorno al cambio climático). 
Hay varios motivos para apostar por las propuestas artísticas fundamentadas en la sostenibilidad fuerte y el decrecimiento. En primer lugar, tal y como hemos expuesto, porque el cambio es cada vez más urgente, y los parches cada vez más inútiles. En segundo lugar, porque es necesario salir de la dicotomía institucionalizada que plantea mantener el sistema actual o colapsar, como si fuera el único sistema posible y fuera de él sólo hubiera el caos y la nada. En esta dicotomía, el concepto de sostenibilidad es entendido como la manera de "sostener" el sistema hegemónico, y el colapso como la barbarie. Pero los indicadores ecológicos, y su demostrada relación con la política y la economía, advierten que es necesario poner en cuestión el sistema, y es necesario poder pensar nuevos futuros y alternativas más sostenibles. En este contexto, el colapso adquiere un nuevo significado. Mientras que la barbarie es un escenario de desorden y simplificación de las sociedades (colapso en su acepción más negativa), en el decrecimiento el colapso es el requisito previo, la salida necesaria del sistema para dar paso a algo diferente (colapso como generador de un orden más estable, tal y como mencionamos en el paralelismo con los procesos de inestabilidad geológica). A este necesario colapso también se refiere Agamben cuando dice que "una Europa como la que yo quiero sólo podría darse cuando la «Europa» realmente existente colapse" (Radisch, 2015). Para Agamben, la creación de un nuevo orden dentro del sistema no resulta eficaz, y es necesario neutralizar el poder mediante la inoperatividad (el llamado proceso destituyente, que encuentra paralelismos con el decrecimento). "Cuando se quiere recuperar la vida, la anarquía, la anomia y la ademia en su verdad, es preciso por lo tanto liberarse antes de la forma que éstas recibieron en la exceptio" (Agamben, 2016). Y para liberarse de la forma, ésta tiene que caer.

El reto que plantea el decrecimiento es tan difícil que muchos lo consideran una utopía, o en el mejor de los casos, un ideal al cual tender (Luffiego y Rabadán, 2000). Paradójicamente, que parezca una teoría política imposible le da legitimidad pues, recordando a Badiou (1999), la política consiste en pensar y practicar lo que la política dominante declara imposible. Pero hay que admitir que resulta más sencillo 
"enverdecer" algo que ya existe que enfrentarse a la "utopía" que supone plantearse un nuevo sistema fuera del actual, sostenible y justo. Requiere de un esfuerzo de imaginación mayor. En coherencia con lo expuesto hasta ahora, los proyectos artísticos enmarcados en la sostenibilidad fuerte juegan un papel más importante en el proceso de cambio hacia sociedades sostenibles. Sin embargo, la apuesta decidida y contundente por este tipo de arte no debe desmerecer las demás propuestas artísticas de carácter ecológico, pese a que se enmarquen en conceptos de sostenibilidad menos intensos y afronten los conflictos ecológicos de una manera más compartimentada. Precisamente porque el reto no es fácil, y porque la respuesta resulta urgente, todas las respuestas hacia un modelo más sostenible (aún sin llegar a ser sostenible) son válidas. Así, los tres tipos de respuestas expuestos pueden ser considerados como fases de un proceso de cambio. Y puesto que nos encontramos en una fase muy inicial de este proceso, cualquier propuesta que suponga un avance es bienvenida, aunque aquella que permita traspasar la frontera de lo (aun) implanteable es deseada y debe de ser potenciada.

\section{Notas}

1. En muchas sociedades que sufren escasez de recursos, la competencia por éstos acaba dinamitando la cohesión social, y esto deriva en conflictos importantes. Como en Ruanda, donde las disputas por la tierra (motivadas por el crecimiento demográfico y agravadas por el deterioro medioambiental y el cambio climático) propició la pérdida de cohesión del tejido social tradicional de la sociedad ruandesa, lo que acabó por desencadenar la guerra (Diamond, 2006, p. 266).

2. Ecognosis es un término utilizado por Timothy Morton para referirse al conocimiento mediante el cual se toma plena conciencia ecológica, o lo que el autor denomina la ecología oscura (dark ecology). Esta toma de consciencia plena pasa por múltiples fases (Morton, 2014, p. 5).

3. El informe Brundtland, originariamente llamado Nuestro futuro común, fue elaborado por distintas naciones en 1987 para la ONU, por una comisión encabezada por la doctora Gro Harlem Brundtland, entonces primera ministra de Noruega. El objetivo era analizar, criticar y replantear las políticas de desarrollo económico globalizador, reconociendo que el avance social se está llevando a cabo a un coste 
medioambiental alto. Este informe introdujo el concepto de desarrollo sostenible, que fue incorporado a todos los programas de la ONU.

4. En el informe Brundtland no se hace diferencia entre los términos de desarrollo y crecimiento (Luffiego y Rabadán, 2000, p. 474).

5. Por ejemplo, en la acción EZLN - NATURE Versus BAYER (2006), contra la unión de las dos multinacionales Bayer y Monsanto.

\section{Referencias}

Agamben. G. (2016, 28 de marzo). Elementos para una teoría de la potencia destituyente. Artillería inmanente. Recuperado de ttps://artilleriainm anente.noblogs.org/post/2016/05/12/giorgio-agamben-elementos-par a-una-teoria-de-la-potencia-destituyente/

Albelda, J., \& Sgaramella, C. (2015). “Arte, empatía y sostenibilidad.

Capacidad empática y conciencia ambiental en las prácticas contemporáneas de arte ecológico.” Ecozona, 6(2), 10-25.

Almarcegui, L. (2015). Descampados, demoliciones y ruinas. En T.

Blanch.(ed.). Topografías Invisibles: estrategias críticas entre Arte y Geografía. Barcelona: Edicions Universitat de Barcelona.

ACNUR Alto Comisionado de las Naciones Unidas para los Refugiados. (2016). Tendencias globales. Desplazamiento forzado en 2015. Forzados a huir. Recuperado de http://www.acnur.es/PDF/Tendenci asGlobales2015.pdf

Badiou, A. (1999). Ética y Política. En: Reflexiones sobre nuestro tiempo. (pp. 27-35). Buenos Aires: Ediciones del Cifrado. Recuperado de: http://www.catedras.fsoc.uba.ar/

Blanch. T. (ed.) (2015). Topografías Invisibles: estrategias críticas entre Arte y Geografía. Barcelona: Edicions Universitat de Barcelona.

CMMAD Comisión Mundial sobre el Medio Ambiente y el Desarrollo (1987). Nuestro futuro común.

Daly, H. (1997). "De la economía del mundo vacío a la economía del mundo lleno". En: R. Goodland (ed.), Medio ambiente y desarrollo 
sostenible: más allá del informe Brundtland (pp. 37-50). Madrid: Trotta.

Demos, T.J. (2012). "Art after nature". Artforum, 50(8), 190-198.

Diamond, J. (2006). Colapso. Por qué unas sociedades perduran y otras desaparecen. Barcelona: Random House Mondadori.

Dotras, O. (2015, 1 de abril). "El ranking de desempleo en los países europeos". La Vanguardia. Recuperado de http://www.lavanguardia.com/vangdata/20150401/54428617678/elranking-de-desempleo-en-los-paises-europeos.html

García-Dory, F (s.f.). Acerca de. Recuperado de http://www.inland.org Goldsworthy, A. (1980). Nature as Material: An Exhibition of Sculpture and Photographs Purchased for the Arts Council Collection by Andrew

Causey. Recuperado de http://www.goldsworthy.cc.gla.ac.uk/extracts/ Goto, R. (2012). Ecology and Environmental Art in Public Place: Talking Tree. Tesis doctoral. Aberdeen: Robert Gordon University.

Recuperado de: http://collinsandgoto.com/wp-content/uploads/2012/ 04/Reiko-PHD-Thesis-Reiko-Goto.pdf

Granés, C. (2011). El puño invisible. Arte, revolución y un siglo de cambios culturales. Madrid: Ed. Taurus.

Iriondo, M. H. (2007). Introducción a la geología (3ra ed.). Argentina: Brujas.

Lasn, K. \& Fleet, D. (2011). The New Spirit of Economics. Recuperado de https://www.adbusters.org/article/the-new-spirit-of-economics

Latouche, S. (2009). Farewell to growth. Cambridge: Polity Press.

Latouche, S. \& Harpagès, D. (2011). La hora del decrecimiento. Barcelona: Octaedro.

Luffiego García, M., \& Rabadán Vergara, J. (2000). "La evolución del concepto de sostenibilidad y su introducción en la enseñanza". Enseñanza de las Ciencias: Revista de Investigación y Experiencias Didácticas, 18(3), 473-486

Martínez Alier, J., \& Roca Jusment, J. (2013). Economía ecológica y política ambiental. México: Fondo de Cultura Económica. 
Meadows, D. H. (1972). Los Límites del crecimiento: informe al Club de Roma sobre el predicamento de la humanidad. México: Fondo de Cultura Económica

Mitchell, J. (1997). "Mitigation in environmental assessment — furthering best practice". Environmental Assessment 5(4), 28-29.

Morton, T. (2016). Dark ecology. For a logic of future coexistence. New York: Columbia University Press.

Norquist, J.O. (2000). Tear it Down! Recuperado de http://www.preservenet. $\mathrm{com} /$ freeways/FreewaysTear.html

N'undo (2011). 100 palabras. Recuperado de http://www.nundo.org/

OECD Organisation for Economic Cooperation and Development. (2015). In It Together: Why Less Inequality Benefits All. Recuperado de http://dx.doi.org/10.1787/9789264235120-en

Radisch, I. (2015, 27 de agosto). "Europa muss kollabieren”. Die Zeit (trad. "Europa debe colapsar" en https://artilleriainmanente.noblogs.org)

Servigne, P. \& Stevens. R. (2015). Comment tout peut s'effondrer. Paris: Seuil.

Speranza, G. (2017). Cronografías. Arte y ficciones de un tiempo sin tiempo. Barcelona: Editorial Anagrama.

Taibo, C. (2016). Colapso. Capitalismo terminal, transición ecosocial, ecofascismo. Madrid: Los Libros de la Catarata.

Viladomiu, À. (2015). 1: Investigaciones experimentales del 'Lugar': del registro al accionismo. En: Blanch. T. (ed.). Topografías Invisibles: estrategias críticas entre Arte y Geografía. Barcelona: Edicions Universitat de Barcelona.

Wade, M. (2017, 8 de abril). Andy Goldsworthy: the man who will lie in the street for his art. The Times. Recuperado de https://www.thetimes.co .uk/article/andy-goldsworth-the-natural-world-is-not-confined-to-fiel ds-and-woods-vx70h9jd5 
Paula Bruna Pérez: Doctoranda del programa de doctorado Estudios Avanzados en Producciones Artísticas, Facultad de Bellas Artes, Universidad de Barcelona

Contact Address: Facultad de Bellas Artes, Calle de Pau Gargallo, 4, 08028 Barcelona

\section{E-mail address: pbp1278@gmail.com}

Àngels Viladomiu Canela: Profesora agregada PSH en la Facultad de Bellas Artes, Universidad de Barcelona

Contact Address: Facultad de Bellas Artes, Calle de Pau Gargallo, 4, 08028 Barcelona

E-mail address: aviladomiu@ub.edu 